\title{
Maternal Anthropometry and Intrauterine Growth Retardation (IUGR) - A Hospital Based Study
}

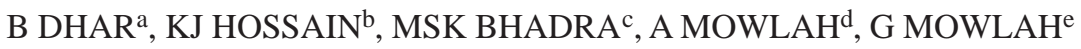

\begin{abstract}
Summary:
This was a prospective observational study conducted on 374 pregnant women who remained in the study beginning from first trimester until gave birth to singleton newborn babies selected from five maternity hospitals located at different regions in the country over a period of thirty months from July 2002 to December 2004. Objectives of the study were: (1) To find out the incidence of IUGR in the hospital based study, (2) To observe the impact of prepregnancy weight and pregnancy weight gain on IUGR, (3) To select appropriate cut off points of pre-pregnancy weight and pregnancy weight gain to identify women at risk for delivering IUGR babies and (4) To observe the association between socio-demographic factors and maternal anthropometry.
\end{abstract}

Twenty one percent women delivered IUGR babies. Mothers who gained $<4 \mathrm{~kg}$ in second trimester and $<5 \mathrm{~kg}$ in third trimester gave birth to significantly higher incidence of IUGR babies (29.1\% and $35.3 \%$ respectively) in comparison

\section{Introduction:}

The birth weight of newborn baby is probably the most important factor that affects the future survival and quality of life ${ }^{1-4}$. It is also a significant determinant of post neonatal, infant and childhood mortality as well as

a. Dr. Bishnupada Dhar, Ph. D., Program Manager(CA\&SS), Directorate General of Family Planning, 6, Kawran Bazar, Dhaka-1215

b. Dr. Kazi Jahangir Hossain, Ph. D., Asstt. Professor, Department of Health Education,, NIPSOM, Mohakhali, Dhaka-1212

c. Mr. Subrata K. Bhadra, MA, Senior Research Associate, NIPORT, Azimpur, Dhaka 1205.

d. Professor Dr. Aleya Mowlah, Ph.D., Institute of Nutrition and Food Science, University of Dhaka.

e. Professor Dr. Golam Mowlah, Ph.D., Institute of Nutrition and Food Science, University of Dhaka.

Address of Correspondence: Dr. Bishnupada Dhar, Ph. D, Program Manager(CA\&SS), Directorate General of Family Planning, 6, Kawran Bazar, Dhaka-1215

Received: 17 March, 2008

Accepted: 6 January, 2010

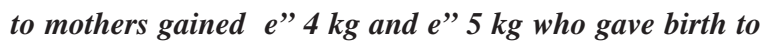
$14.4 \%$ and $9.3 \%$ IUGR babies $(p<.001)$. Maternal weight for height in the lower range of normalcy at early pregnancy was associated with an increased risk of IUGR when compare to normal or over weight for height group of mothers (30.6\% vs. 9.5\%; $p=<.001)$. The study revealed that combination of $<90$ percent of standard weight for height and net weight gain per week $<125 \mathrm{gm}$ have strong negative influence on foetal growth (39.5\% IUGR babies). On the contrary, combination of $e$ " 110 percent of weight for height and weekly weight gain of $e^{\text {” } 150 \mathrm{gm} \text { have }}$ significant positive impact on foetal growth (6.7\% IUGR). For total weight gain, best cut off point for identifying risk women of delivering IUGR babies was recommended 8.5 $\mathrm{kg}$ and that for prepregnancy or first trimester weight was $47.5 \mathrm{~kg}$.

Key words: Low birth weight, intrauterine growth retardation, Anthropometry

(J Bangladesh Coll Phys Surg 2010; 28: 73-80)

morbidity ${ }^{4-5}$. For these reason, birth weight has long been a subject of clinical epidemiological investigations and an area of public health interest. In particular, considerable attention has been focused on the causal determinants of birth weight, especially of low birth weight (LBW), for identifying the potentially modifiable factors. Birth weight is governed by two major processes: duration of gestation and intrauterine growth retardation (IUGR). LBW is thus caused by either a short gestation period or retarded intrauterine growth (or combination of both $)^{6}$. Most of the LBW in industrialized countries is due to pre- term ( $<37$ weeks of gestation) birth, while majority of LBW in developing countries is due to $\mathrm{IUGR}^{7-8}$. The concept of classification of infants into risk groups (IUGR groups) according to birth weight and gestational age first emerged with the publication of intrauterine growth standards in $1963^{9}$. Since then several standards have been published in different countries ${ }^{10-11}$. 
Premature infants and IUGR infants should be studied as separate groups, because they show different patterns of growth, morbidity and mortality. Infants who are growth retarded have higher rates of long-term developmental or physical morbidities, including growth deficiencies. On the other hand, infants who have grown at appropriate rates during gestation, but are born early have higher rates of neonatal mortality and infectious disease mortality during infancy, but if they survive, exhibit fewer long-term developmental abnormalities ${ }^{12-}$

13 From a programmatic viewpoint these differences have enormous implications for intervention strategies and limitations of the approach of nutritional recovery of IUGR infants in early childhood ${ }^{14-15}$.

In Bangladesh, incidence of LBW is unacceptably high $^{8,16-20}$. And majority of these LBW babies is due to IUGR. Moreover, among normal weighing babies (e"2.5 kg) certain percentage might suffer from growth retardation and there would also be a proportion of infants who are both growth retarded and preterm, and these babies would be at high risk of neonatal mortality and subsequent developmental and physical morbidities. If we consider these issues as well, it can easily be assumed that incidence of growth retarded infants is higher than LBW infants in the country. But unfortunately, no study has yet been conducted to identify the incidence as well as determinants of IUGR.

From many studies in developed and developing countries it is observed that maternal nutritional factors (as estimated from maternal anthropometry) play significant role for the occurrence of IUGR ${ }^{6}$. Therefore, the primary objective of the present study is to find out the incidence of IUGR and to observe the association between IUGR and maternal nutritional factors in terms of maternal weight. To observe the distal or indirect effect of socio-demographic factors on IUGR, relationship between maternal anthropometry and sociodemographic factors is also attempted to examine.

\section{Materials and method:}

This was a prospective observational study conducted on pregnant women beginning from first trimester until delivery at four district level Mother and Child Welfare Centres (MCWC) and Ad-din hospital at Dhaka to examine the relationship between maternal modifiable factors and intrauterine growth retardation. The four MCWCs are located at Comilla, Pabna, Bogra and
Jamalpur. These are government maternity hospitals. Comprehensive essential obstetric care (EOC) services (including caesarian section and blood transfusion) are provided from these centers since 1995. There are 98 such centers in the country, out of which 63 centres are located at district head quarter. Doctors and paramedics are well trained from medical college hospitals. Sophisticated equipments are provided in each center by UNFPA. Record keeping system is unique in these centres. Anthropometric measurements are taken correctly. As these centers are located at district head quarter, urban, periurban as well as rural women have the scope to enjoy the facilities of these centers. To ensure quality data, the investigators decided to collect data from such four centers. Four centers were selected randomly. In addition to government facilities at district level, investigators also selected a similar nongovernment hospital at Dhaka metropolitan city. This is Ad-din hospital, a specialized maternity hospital located at the centre of the city (Mag bazaar area). Obstetric services are provided by specialist doctors. All relevant maternal information is properly recorded in this institute. As the hospital is not an expensive one, in addition to socio-economically better off women, large number of middle and lower class pregnant women also usually attend this hospital for antenatal care and delivery service.

Data were collected over a period of 30 months from July 2002 to December 2004.

Pregnant women who attended selected MCWCs and Ad-din hospital for ante natal care from first trimester of pregnancy (at or before 12 weeks of gestation), comprised the study population. Among the study population who joined the study from the early stage of pregnancy, also attended the centres at mid pregnancy (20 to 24 weeks of pregnancy) and finally gave birth to normal singleton baby in these centres were the study subjects of the study. A total of 2055 pregnant women were booked initially at the early stage of pregnancy but at the final stage of data colection, three hundred and seventy four women delivered singleton live birth newborns in the selected service centres and these 374 mothers and their newborns were taken as the study subjects. Subjects who gave birth to still born babies ,multiple pregnancies and pregnant women who had any medical complication (e.g. diabetes mellitus, high blood pressure, heart disease, chronic lung disease, jaundice 
and other debilitating diseases) were excluded from the study.

Intrauterine growth retarded newborns were classified according to weight for gestational age standards developed by Lubchenco et $\mathrm{al}^{9}$. Thus, 295 (79 percent) babies were found non- growth retarted or normal and 79 (21 percent) were found growth retarded.

Data were collected through interviews by paramedics under direct supervision and monitoring of doctors of the centres. Initially investigator (first author) visited all the centres and trained the doctors and paramedics of the centres about data collection technique. The subjects were informed about the nature of the study and consent was taken from them. Information about certain socio-demographic characteristics (age, education, monthly family income and occupation) and anthropometric measures were recorded through the structured questionnaire. To ensure quality data collection, the investigators visited each centre at two weeks interval and checked each and every filled up questionnaire. Any inconsistency which was identified either was discarded or if practicable, corrected. Thus no inappropriate data was included in the sample. Though information on socio-demographic characteristics was recorded, these variables were not used in the analyses to examine their relationship with IUGR. However, effort was under taken to examine the association between socio-demographic variables and maternal anthropometry in order to identify whether there is any indirect relationship existing between these variables and intrauterine growth.

Mothers' and babies' anthropometric parameters were recorded according to standardized techniques as described by Jellife and Jellife ${ }^{21}$. Mothers' weight measurements were undertaken at booking time (at or before 12 weeks of gestation), at second trimester (2024 weeks of gestation) and at term (before delivery). Body Mass Index (BMI) was calculated from weight and height. Immediate post partum weight of the women and anthropometric measurements of newborns (weight, head circumference, chest circumference and crown heel length) were recorded just after their birth. We identified total weight gain, second and third trimester weight gains to observe their effect on foetal growth. Like many other authors, weight at booking time was treated as prepregnancy weight. Percent of standard weight for height was calculated to assess the incidence of IUGR across various weight for height groups. We also emphasized to examine the association between net rate of maternal weight gain (instead of overall rate of weight gain) and intrauterine growth. Since weight gains are generally far smaller in the first than in the second and third trimesters, women with preterm deliveries will have had a lower overall rate of gain, on average than those delivered at term. Moreover, foetal weight increases exponentially, with highest gains in the third trimester, while the overall rate of maternal weight gain is fairly constant after the first trimester. Thus, with advancing gestation, the portion of overall gain attributable to maternal tissues and nutritional stores diminishes to that of increased foetal size. Associations between overall rate of weight gain and birth weight may therefore, reflect the effect of foetal growth, rather than maternal nutrition per se. Thus, it is logical to examine the relationship between net rate of weight gain and intrauterine growth. Net weight gain was calculated by subtracting immediate post partum weight from term weight and net rate of weight gain was calculated by dividing net weight gain by gestational age. We defined low net rate of weight gain as $<125 \mathrm{gm} /$ week and normal as e”150gm/week. Besides we also defined low and normal net weight gains as $<4 \mathrm{~kg}$ as e" $4 \mathrm{~kg}$. BMI was also categorized as low (<20) and normal (e” 20).

Data were analyzed using SPSS software (11.5 version). Chi-square test was carried to compare the differences in proportions. Sensitivity and specificity analysis was under taken to select appropriate cut off points of maternal weight gain and minimum prepregnancy weight for identifying risk women of delivering IUGR babies.

This study has certain limitations like many other studies. This is a hospital based study, so the findings of the present study can not be generalized. Another limitation of the study is that, those who did not participate or loss to follow up after initial booking, their pregnancy outcomes could not be compared with 
those who completed their participation in the study. Thus, this non- participation group or loss to follow up group whether underestimated or overestimated the study result could not be ascertained. This study also did not include the elate group of women who usually give birth to their newborns at most modern and expensive hospitals and clinics. However, most of this elite group of women is most likely give birth to nongrowth retarded babies; their absence from the study is not a major concern. Finally, no supplementation was given to the women to investigate the effect of qualitative and quantitative effect of food supplementation on pregnancy outcome. Therefore, inference cannot be drawn from this study about what type and what quantity of food supplementation is needed for the individual subject.

\section{Results:}

Low maternal weight gain both in second and third trimesters ( $<4 \mathrm{~kg}$ vs. e" $4 \mathrm{~kg}$ and $<5 \mathrm{~kg}$ vs. e” $5 \mathrm{~kg}$ respectively for second and third trimesters) had significant effect $(\mathrm{p}<.001)$ on the prevalence of IUGR (TablesI\&II). Influence of percent of standard weight for height both at first and third trimesters (at term) on IUGR was examined and presented in tables III and IV. It is observed that those mothers who were at $<90$ percent of standard weight for height at first trimester gave birth to 30.6 percent IUGR babies and those who were e" 110 percent of standard weight for height at the beginning of pregnancy delivered only 9.5 percent of IUGR babies. Similarly, at term who attained $<100$ percent of standard weight for height delivered 29.6 percent of IUGR babies and who attained e" 110 percent of standard weight for height gave birth to only 6 percent IUGR babies $(\mathrm{p}<.001)$.

\section{Table-I}

Maternal weight change between $1^{\text {st }}$ and $2^{\text {nd }}$ trimesters and incidence of IUGR

\begin{tabular}{lccc} 
Weight change & No. of & \multicolumn{2}{c}{ Non-IUGR and } \\
between 1st and & cases & \multicolumn{2}{c}{ IUGR babies } \\
2nd trimester & & Non-IUGR & IUGR \\
& & $\%$ & $\%$ \\
\hline$<4 \mathrm{~kg}$ & 172 & 70.9 & 29.1 \\
e" 4kg & 202 & 85.6 & 14.4 \\
\hline & $\chi^{2}-12.0,(\mathrm{df}-1, \mathrm{p}<.001)$
\end{tabular}

Table-II

Maternal weight change between 2nd and 3rd trimesters and incidence of IUGR

\begin{tabular}{|c|c|c|c|}
\hline \multirow{2}{*}{$\begin{array}{l}\text { Weight change } \\
\text { between } 2^{\text {nd }} \text { and } \\
\text { 3rd trimester }\end{array}$} & \multirow[t]{2}{*}{$\begin{array}{l}\text { No. of } \\
\text { cases }\end{array}$} & \multicolumn{2}{|c|}{$\begin{array}{l}\text { Non-IUGR and } \\
\text { IUGR babies }\end{array}$} \\
\hline & & $\begin{array}{c}\text { Non-IUGR } \\
\%\end{array}$ & $\begin{array}{c}\text { IUGR } \\
\%\end{array}$ \\
\hline$<5 \mathrm{~kg}$ & 170 & 64.7 & 35.3 \\
\hline e"5kg & 204 & 90.7 & 9.3 \\
\hline
\end{tabular}

Table-III

Influence of maternal weight for height early in pregnancy (up to 12 weeks of gestation) on IUGR

\begin{tabular}{|c|c|c|c|}
\hline \multirow{2}{*}{$\begin{array}{l}\text { Maternal weight } \\
\text { for height in early } \\
\text { pregnancy (percent) }\end{array}$} & \multirow[t]{2}{*}{$\begin{array}{l}\text { No of } \\
\text { cases }\end{array}$} & \multicolumn{2}{|c|}{$\begin{array}{l}\text { Non-IUGR and } \\
\text { IUGR babies }\end{array}$} \\
\hline & & $\begin{array}{c}\text { Non-IUGR } \\
\%\end{array}$ & $\begin{array}{c}\text { IUGR } \\
\%\end{array}$ \\
\hline$<90$ & 134 & 69.4 & 30.6 \\
\hline $90-99$ & 99 & 76.8 & 23.2 \\
\hline 100-109 & 66 & 87.9 & 12.1 \\
\hline e”110 & 74 & 90.5 & 9.5 \\
\hline
\end{tabular}

$\chi^{2}-16.7,(\mathrm{df}-3, \mathrm{p}<.001)$

Table-IV

Influence of maternal weight for height at term on IUGR babies

\begin{tabular}{|c|c|c|c|}
\hline \multirow{2}{*}{$\begin{array}{l}\text { Maternal weight } \\
\text { for height at term } \\
\text { (percent) }\end{array}$} & \multirow[t]{2}{*}{$\begin{array}{l}\text { No of } \\
\text { cases }\end{array}$} & \multicolumn{2}{|c|}{$\begin{array}{l}\text { Non-IUGR and } \\
\text { IUGR babies }\end{array}$} \\
\hline & & $\begin{array}{c}\text { Non-IUGR } \\
\%\end{array}$ & $\begin{array}{c}\text { IUGR } \\
\%\end{array}$ \\
\hline$<100$ & 223 & 70.4 & 29.6 \\
\hline $100-<110$ & 83 & 89.2 & 10.8 \\
\hline e”110 & 67 & 94.0 & 6.0 \\
\hline
\end{tabular}

Table V demonstrated that mothers whose net weight gain was < 125gm per week delivered 27.4 percent IUGR babies and those who gained e" $150 \mathrm{~kg}$ per week gave birth to 11.8 percent IUGR babies $(\mathrm{p}=<.005)$.

From the tables, so far presented it is revealed that maternal weight gain and first trimester weight status 
(proxy of prepregnancy weight) have clear positive significant influence on foetal growth.

\section{Table-V}

Gestational net weight gain per week and its influence on IUGR.

\begin{tabular}{lccc} 
Gestational weight & No of \\
gain per week (gm) & cases & \multicolumn{2}{c}{$\begin{array}{c}\text { Non-IUGR and } \\
\text { IUGR babies }\end{array}$} \\
\cline { 2 - 4 } & & Non-IUGR & IUGR \\
\cline { 2 - 4 } & 215 & 72.6 & 27.4 \\
\hline$<125$ & 74 & 86.5 & 13.5 \\
$125-<150$ & 85 & 88.2 & 11.8 \\
\hline e”150 & &
\end{tabular}

$\chi^{2}-12.2,(\mathrm{df}-2, \mathrm{p}<.005)$

Table VI explains the combination effect of maternal net rate of weight gain and percent of standard weight for height at early pregnancy on intrauterine growth. It is revealed that women who had initial weight for height less than 90 percent of standard and net weight gain was also less than 125gm per week gave birth to more than
39 percent IUGR babies. On the other hand, whose initial weight for height was e"110 percent and rate of weight gain less than 125 gm delivered 14 percent IUGR babies. Again, when initial weight was below 90 percent but rate of weight gain was either equal to or above 150 gm per week delivered 18.5 percent IUGR babies. Women with e"110 percent of weight for height who also gained e" 150 gm per week delivered only 6.7 percent IUGR babies.

When it is established that maternal prepregnancy weight and weight gain during pregnancy are the two most important determinants of IUGR, then another task is to find out the appropriate cut off points for prepregnancy weight and weight gain during pregnancy to identifying risk women for delivering IUGR babies.

From sensitivity and specificity analysis it is observed that, for predicting risk women of delivering IUGR babies the best cut off points for total weight gain and prepregnancy weight should be $8.5 \mathrm{~kg}$ and $47.5 \mathrm{~kg}$ respectively (table VII).

What relationship does exist between maternal anthropometry and socio demographic factors is presented in table VIII. It is obvious from the study that, socio-demographically better off women had higher mean anthropometric values for weight, height and BMI.

Table-VI

\begin{tabular}{|c|c|c|c|c|c|c|c|}
\hline & Incide & nce of IUGR by & initial weigl & for height and & eight gain $p$ & er week. & \\
\hline \multirow{3}{*}{$\begin{array}{l}\text { Initial weight for } \\
\text { height (percent) }\end{array}$} & \multirow{3}{*}{$\begin{array}{r}\text { No of } \\
\text { cases }\end{array}$} & \multicolumn{6}{|c|}{ Weight gain per week (gm) } \\
\hline & & \multicolumn{2}{|c|}{$<125$} & \multicolumn{2}{|c|}{$125-<150$} & \multicolumn{2}{|c|}{$\geq 150$} \\
\hline & & Non-IUGR (\%) & IUGR (\%) & Non-IUGR (\%) & IUGR (\%) & Non-IUGR (\%) & IUGR (\%) \\
\hline$\overline{<90}$ & 134 & 60.5 & 39.5 & 90.5 & 9.5 & 81.5 & 18.5 \\
\hline $90-99$ & 99 & 72.0 & 28.0 & 70.0 & 30.0 & 89.7 & 10.3 \\
\hline $100-109$ & 66 & 85.7 & 14.3 & 88.2 & 11.8 & 92.9 & 7.1 \\
\hline$\geq 110$ & 74 & 86.0 & 14.0 & 100.0 & 0.0 & 93.3 & 6.7 \\
\hline
\end{tabular}

Table-VII

\begin{tabular}{|c|c|c|c|c|c|c|}
\hline \multicolumn{7}{|c|}{$\begin{array}{l}\text { Sensitivity and specificity analysis for selection of cut off points of total weight gain and } \\
\text { prepregnancy weight for IUGR. }\end{array}$} \\
\hline Total weight gain (gm) & Sensitivity & Specificity & $\begin{array}{l}\text { Positive } \\
\text { predictive } \\
\text { value }\end{array}$ & $\begin{array}{c}\text { Negative } \\
\text { predictive } \\
\text { value }\end{array}$ & Odds ratio & $\begin{array}{c}95 \% \\
\text { confidence } \\
\text { interval }\end{array}$ \\
\hline$<8000$ & 62.0 & 76.9 & 41.8 & 88.3 & 5.4 & $3.1-9.5$ \\
\hline$<8500$ & 73.4 & 63.0 & 34.7 & 89.8 & 4.7 & $2.6-8.6$ \\
\hline$<9000$ & 75.9 & 56.6 & 31.9 & 89.8 & 4.1 & $2.3-7.6$ \\
\hline \multicolumn{7}{|l|}{ First trimester weight } \\
\hline$<45$ & 58.2 & 61.3 & 28.7 & 84.5 & 2.2 & $1.3-3.8$ \\
\hline$<47.5$ & 76.0 & 51.2 & 29.4 & 88.8 & 3.3 & $1.8-6.1$ \\
\hline$<50$ & 84.8 & 44.4 & 29.0 & 91.6 & 4.4 & $2.2-9.4$ \\
\hline
\end{tabular}




\section{Table-VIII}

Mean anthropometric values for different levels of socio-demographic characteristics of mothers.

\begin{tabular}{lccc} 
Variables & $\begin{array}{c}\text { First } \\
\text { trimester } \\
\text { weight (kg) }\end{array}$ & $\begin{array}{c}\text { First } \\
\text { trimester } \\
\text { BMI (unit) }\end{array}$ & $\begin{array}{c}\text { Height } \\
(\mathrm{cm})\end{array}$ \\
\hline $\begin{array}{l}\text { Mothers' age } \\
<20\end{array}$ & 44.3 & 19.7 & 149.9 \\
$20-24$ & 46.7 & 20.3 & 151.7 \\
25-29 & 48.8 & 21.1 & 152.0 \\
e” 30 & 50.1 & 21.5 & 152.4 \\
Education & & & \\
none & 41.2 & 19.2 & 147.7 \\
Primary & 44.1 & 19.6 & 149.9 \\
Secondary & 46.2 & 20.1 & 151.3 \\
incomplete & & & \\
Secondary & 49.4 & 21.2 & 152.6 \\
complete or more & & & \\
Income & & & \\
$<=3000 /-$ & 44.6 & 19.6 & 150.5 \\
3000-6000/- & 46.5 & 20.3 & 151.1 \\
6000-9000/- & 47.5 & 20.6 & 151.7 \\
$>$ 9000/- & 49.9 & 21.3 & 152.9 \\
Family size & & & \\
2 & 48.5 & 21.3 & 150.5 \\
3-4 & 48.3 & 20.9 & 152.0 \\
5-6 & 46.6 & 20.2 & 151.7 \\
$\geq 7$ & 46.9 & 20.2 & 151.9 \\
Occupation & & & \\
Labour & 44.3 & 19.6 & 150.0 \\
Business & 48.3 & 20.7 & 152.3 \\
Service & 47.7 & 20.7 & 151.8 \\
\hline
\end{tabular}

\section{Discussion:}

Our study findings demonstrated that low maternal weight gain increases the risk of IUGR. Many other more or less similar studies also revealed the fact that, low total weight gain, low trimester weight gain, Low BMI, low weight for height increases the risk of IUGR and low birth weight. Smith reported that maternal starvation during the last two trimesters of pregnancy decreases average birth weight by $240 \mathrm{gm}$; however the women he studied were exposed to severe famine ${ }^{22}$. We have observed in our study that, low weight gain in second trimester $(<4 \mathrm{~kg})$ was associated with approximately double the risk of intrauterine growth retardation and four times the risk with low weight gain $(<5 \mathrm{~kg})$ in third trimester. Reason for considering low weight as $<4 \mathrm{~kg}$ and $<5 \mathrm{~kg}$ is that mean weight gain in our study at second and third trimesters were found to be about $4 \mathrm{~kg}$ and $5 \mathrm{~kg}$ respectively. Strauss R.S. and Diet W.H. in their study considered low weight gain as $<0.3 \mathrm{~kg}$ per week both for second and third trimester, and observed approximately double the risk of IUGR with low weight gain ${ }^{23}$. Abram and Selvin demonstrated that low maternal weight gain $(<5.7 \mathrm{~kg})$ was associated with decreased birth weights ranging from 48 to $248 \mathrm{gm}$ depending on the pattern of weight gain in other trimesters ${ }^{24}$. Other two studies also confirmed that low prenatal weight gain significantly decreased the birth weight and increased the number of infants born with growth retardation ${ }^{25 \& 26}$.

Besides impact of weight gain on foetal growth, we also evaluated the influence of various combinations of weight gain and initial percent of standard weight for height on intrauterine growth. Weight gain was expressed as net rate of weight gain. The study revealed that combination of lowest weight gain $(<125 \mathrm{gm}$ per week) and lowest percent of standard weight for height ( $<90$ percent) responsible for highest risk (39.5 percent) of giving birth to growth retarded babies. On the contrary, women who gained 125 - <150gm per week and also had e"110 percent of standard weight for height delivered not a single IUGR babies (Table VI). In column 6 of table VI incidence of IUGR was found to be 0.0 at initial weight for height e" 110 and weight gain per week of $125<150 \mathrm{gm}$, but reduction of incidence of IUGR in column 6 is inconsistence across the percent of initial weight for height. On the other hand in column 8 of the table it is revealed that there is gradual decrease of incidence of IUGR for mothers ( who gained e" 150gm) whose initial weight for height gradually increases from $<90$ percent to e" 110 percent. Therefore, we concluded that mothers whose weight gain was e" $150 \mathrm{gm}$ per week and initial weight for height was e" 110 are the least risk group for giving birth to IUGR babies.

From the table we also observed that, women who began pregnancy with low weight for height $(<90$ percent) but weight gain was e"150gm per week and women who gained weight as $<125 \mathrm{gm}$ per week but initial weight for height was above 110 percent had intermediate risk for giving birth to IUGR babies. This 
important finding strongly supports the supposition of Garn that prepregnancy weight for height and pregnancy weight gain are independent and completely additive (and subtractive) in their effect on intrauterine growt $\mathrm{h}^{27}$. Thus, it can reasonably be argued that low prepregnancy weight and low weight gain combinly seriously affect the foetal growth.

After establishing the role of weight gain and prepregnancy weight on IUGR, we attempted to find out the appropriate cut off points of weight gain and prepregnancy weight for identifying risk women who will most likely deliver IUGR babies. Sensitivity and specificity analysis was carried out to select appropriate cut off points. Sensitivity is defined as the ability to identify correctly individuals who have a specific condition, while specificity is defined as the ability to correctly predict individuals who do not have a specific condition. In table VII, three cut off points (8000, 8500 and $9000 \mathrm{~g}$ ) of total weight gain was chosen to recommend the best total weight gain for prediction of IUGR babies in our country. At a cut off point of $8 \mathrm{~kg}$ weight gain, among 79 IUGR babies, 49 can be identified. When the cut off point is raised to $8.5 \mathrm{~kg}$, 58 cases of IUGR babies were identified; again at a cut off point of $9 \mathrm{~kg}$ the number is raised to 60 . One should select such a cut off point for any indicator that identifies maximum number of the cases that one needs to identify. At the same time number of false positive cases should also be minimum so that overburden to the programme can be avoided. Taking in to consideration all these points we recommend a cut off point of $8.5 \mathrm{~kg}$ for weight gain below which a significant number of women are at risk of giving birth to IUGR babies. Similarly, for prepregnancy weight from the study finding, we recommend that a woman should be considered at risk for giving birth to IUGR babies when her prepregnancy weight was found to be less than $47.5 \mathrm{~kg}$.

Anthropometric indicators are diagnostic or reflective indicators identify women with nutritional problems, but donot reveal the underlying cause or determinant of the problem or the best interventions to solve the problem. Therefore, we also attempted to examine the relationship between maternal anthropometry and sociodemographic factors to suggest appropriate intervention strategies for reducing incidence of IUGR and LBW. From table VIII, it is revealed that mothers of low socio-economic group (younger age, low income, no or minimum education, labourer group of husbands) have low mean anthropometric values for weight, height, and BMI. This finding leads us to think that though anthropometric indicators, particularly prepregnancy weight and pregnancy weight gain are the two most important determinants of pregnancy outcomes; these are only the proximal causes of the problem. The more distal, i.e. the underlying and basic causes in Bangladesh like other developing countries are the sociodemographic factors which include maternal age, house hold food insecurity, lack of maternal care, lack of access to quality antenatal and other health services, improper sanitation and hygiene, lack of education, gender discrimination etc. To improve the pregnancy outcomes in respect to both mother and baby the above mentioned basic causes should be addressed properly.

\section{Conclusion:}

To reduce the incidence of IUGR, short-term strategy should be towards the improvement of nutritional status of women before pregnancy or during pregnancy by providing adequate food supplementation and antenatal care services. It is recommended that for favourable pregnancy outcome, minimum prepregnancy or first trimester weight should be $47.5 \mathrm{~kg}$ and minimum total pregnancy weight gain should be $8.5 \mathrm{~kg}$. The more important one is to uplift the socio-economic condition and socio-demographic characteristics of mass population particularly of women of reproductive age through multisectoral developmental approach for a sustainable improvement of maternal health and nutritional status through which incidence of IUGR can be reduced significantly.

\section{Acknowledgements:}

We are grateful to the authorities of four MCWCs (Comilla, Pabna, Bogra and Jamalpur) and Ad-din hospital at Dhaka for their cooperation in collecting data from these centres. We express our gratitude to doctors and paramedics who sincerely and patiently collected quality data. Finally, we expressed our sincere gratitude to the mothers for their particpation as well as allowing us to examine their newborns.

\section{References:}

1. Habicht J.P., Lechtig A., Yarborugh C. et al. 1974. Maternal nutrition, birth weight, and infant mortality. In: Size at birth. (Ciba Foundation Symposium 27), Amsterdam, Elsevier, 353-378.

2. Kaminski,M.et al. 1973. Prediction of LBW and prematurity by a multiple regression analysis with maternal characteristics 
known since the beginning of the pregnancy. International journal of epidemiology, 2:195-204.

3. Lechtig A. et al. 1977. Low birth weight babies: Worldwide incidence, economic cost and programme needs. In: Rooth G. Engstrom L. eds. Perinatal care in developing countries. Uppsala, Perinatal research laboratory and World Health Organization

4. Mc Cormick M.C. 1985. The contribution of low birth weight to infant mortality and childhood morbidity. New England journal of medicine, 312:82-90.

5. Goldenberg R. and Prentice AM. 1994. Maternal and foetal determinants of adult disease. Nutrition reviews 52,191-200.

6. Kramer M.S. 1987. Determinants of low birth weight. Methodological assessment and meta- analysis. Bull WHO 65 (5): 663-737.

7. Villar J., Belizan J.M. 1982. The timing factor in the pathophysiology of the intrauterine growth retardation syndrome. Obstet Gynecol Survey, 37: 499-506.

8. Karim E. and Taylor C.G.N. 1997. The association between birth weight, socio-demographic variables and maternal Anthropometry in an urban sample from Dhaka, Bangladesh, Annals of human biology, 24; vol. 5: 387-401.

9. $\quad$ Lubchenco L.O, Hansman C., Dressler M and Boyd E. 1963. Intrauterine growth as estimated from live born birth weight data at 24 to 42 weeks of gestation. J pediatrics, 32: 793800 .

10. Pusey V.A., Haworth J.C. 1969. The relation between birth weight and gestational age for a Winnipeg hospital population. Can Med Assoc J; 100:842-845.

11. Brenner W.E., Edelman D.A., Hendricks CH. 1976. A standard fetal growth for the United States of America. Am J Obstet Gynecol 126: 555-564.

12. Westwood, M., Kramer, M.S., Muntz, D, Lovett, J.M., Watters, G.V. 1983. Growth and development of full-term nonasphyxiated small-for-gestational age newborns: Followup through adolescence. Pediatrics71:376-382.

13. Victoria, C.G., Barros, F.C., Vaughan J.P., Teixeira, A.M.B. 1987. Birth weight and infant mortality: A longitudinal study of 5914 Brazilian children. International journal of epidemiology 16: 239-245.

14. Prada J., Tsang R. 1998. Biological mechanisms of environmentally induced causes in IUGR. European Journal of Clinical Nutrition 52 (S1): S21-S28.
15. Hass J., Balcazar H., Caulfield L. 1987. Variations in early neonatal mortality for different types of foetal growth retardation. American Journal of Physical Anthropology 76: 467-473.

16. Dhar B., Mowlah G., Kabir DME. 2003. Newborn Anthropometry and its Relationship with Maternal Factors. Bangladesh Med. Res. Counc. Bull. 29(2): 48-58.

17. Begum R., Barua S. 1996. Birth weight in relation to other anthropometric indices and some biological and socioeconomic factors. A study in city hospital, Bangladesh. Journal of Nutrition, vol. 9, nos 1 and 2. Institute of Nutrition and Food Science, University of Dhaka, Bangladesh.

18. Canosa C.A. 1989. Intrauterine growth retardation in India and Bangladesh. Edited by Jacques Senterre. Nestle Nutrition Workshop Series, vol. 18, Nestle ltd. pp 183-204.

19. Nahar N., Afroza S., Hossain M. 1998. Incidence of LBW in three selected communities in Bangladesh Medical Research Council, Bull. 24(2), 49-54.

20. National Food and Nutrition Policy, Bangladesh, 1997.

21. Jellife DB and Jellife EFP. 1989. The assessment of the nutritional status of the Community, Oxford University Press, New York, pp.64-104.

22. Smith C.A. 1947. Effects of maternal undernutrition upon the newborn infant in Holland (1944-1945). J. Pediatr. 30: 229-243.

23. Strauss R. S. and Diet W.H. 1999. Low maternal weight gain in the second or third trimester increases the risk for intrauterine growth retardation. J. Nutr. 129:988-993.

24. Abrams B. and Selvin S. 1995. Maternal weight gain pattern and birth weight. Obstet. Gynecol.86: 163-169.

25. Hickey C.A., Cliver S.P., Mcneal S.F., Hoffman H.J. and Goldenberg R.L. 1996. Prenatal weight gain patterns and birth weight among nonobese black and white women. Obstet. Gynecol. 88:490-496.

26. Lawton F.G., Manson G.C., Kelly K.A., Ramsay I.N. and Morewood G.A. 1988. Poor maternal weight gain between 28 and 32 week gestation may predict small-for-gestational age infants. Br. J. Obstet. Gynecol. 95: 884-887.

27. Garn Stanley. 1991. Prepregnancy weight. In: Maternal nutrition and pregnancy outcomes: Anthropometric assessment, Scientific Publication No. 529, Washington DC, Pan American Health Organization, edited by Krosovec K. and Anderson M. 